\title{
NANOPARTICLES SHAPE EFFECT ON VISCOSITY AND THERMAL CONDUCTIVITY OF IONIC LIQUIDS BASED NANOFLUIDS
}

\author{
Kevin Main ${ }^{1}$, Brandon Eberl ${ }^{1}$, Daniel McDaniel ${ }^{1}$, Amitav Tikadar ${ }^{2}$, Titan C. Paul ${ }^{1, *}$, Jamil A. Khan ${ }^{2}$ \\ ${ }^{1}$ University of South Carolina Aiken, Aiken, SC 29801, USA \\ ${ }^{2}$ University of South Carolina, Columbia, SC 29208, USA
}

\begin{abstract}
Ionic liquids (ILs) are considered a potential candidate for a heat transfer fluid (HTF) in concentrated solar power (CSP) applications. There are already many CSP sites in operation throughout the world. These complex energy systems use various subsystems such as mirrors and lenses to concentrate solar energy onto a central collector. These CSP sites rely on having a stable HTF in order to maintain high energy storage capacity and to reduce costs. This research seeks to develop a robust set of workable data that can be used to better understand the nanoparticles shape effect on viscosity and thermal conductivity of ionic liquids (ILs) based nanofluids. ILs based nanofluids were prepared by pouring 1-Butyl-3-methylimidazolium bis(trifluoromethylsulfonyl) imide $\left(\left[\mathrm{C}_{4} \mathrm{mim}\right]\left[\mathrm{NTf}_{2}\right]\right.$ ) base IL and $\mathrm{Al}_{2} \mathrm{O}_{3}$ nanoparticles. Three different particle shapes (platelets, blades, and spherical) were used to prepare the $1 \mathrm{wt} \%$ ILs based nanofluids. Experimental results shows that the needleshaped nanoparticle provided the greatest effective thermal conductivity compared to the base ILs.
\end{abstract}

KEYWORDS: Concentrated Solar Power (CSP); Heat Transfer Fluid (HTF); Ionic Liquids (ILs); Nanoparticles; Nanofluids.

\section{INTRODUCTION}

Ionic liquids (ILs) are completely composed of ions (organic cation and organic or inorganic anions) and liquids at room temperature [1]. ILs are used in a wide range of industry and engineering-based applications, because of their beneficial thermophysical properties. Low volatility, low flammability, and high thermal stability of the ILs also make them potentially ideal candidates for use as heat transfer fluids [2-3]. The high thermal stability of this type of heat transfer fluids (HTFs) makes it optimal for use in Concentrating Solar Power (CSP) systems, where sunlight is concentrated in a single point from a large area by using mirrors or lenses [4]. In CSP systems, high thermal stability of HTFs is necessary in order to increase efficiency of the system.

Using the concept of nanofluids discussed by Choi et al. [5], nanoparticles can be introduced into the base ILs in order to improve the thermophysical property of the HTFs. It was already reported that ILs based nanofluids show enhanced thermophysical properties [6-8] and thermal performance [9]. Castro et al. [6-7] have reported 5 to $35 \%$ thermal conductivity enhancement and $8 \%$ heat capacity enhancement of ILs based nanofluids with multiwall carbon nanotubes (MWCNTs) and several ILs. Paul et al. [8-9] have studied the thermophysical properties and thermal performance of ILs based nanofluids comprising different ILs and $\mathrm{Al}_{2} \mathrm{O}_{3}$ nanoparticles. Up to $11 \%$ enhancement of thermal conductivity, $63 \%$ has been observed for the $2.5 \%$ (weight\%) $\mathrm{Al}_{2} \mathrm{O}_{3}$ enhanced ILs compared to base ILs. However, previous research on ILs based nanofluids are with single shape (spherical) nanoparticles, and particle shape effect on thermophysical properties of ILs based nanofluids has not been studied. There are few studies on particle shape effect on thermophysical properties, and all of them are water/ethylene glycol based nanofluids [10-11]. Timofeeva et al. [10] have studied four different shape of $\mathrm{Al}_{2} \mathrm{O}_{3}$ nanoparticles effect of water based nanofluids and reported that enhancement of thermal conductivity and viscosity is due to the particle shape as well as the particle surface area. Here this study expanded upon the results from Paul et al. [8-9] research by evaluating whether $\mathrm{Al}_{2} \mathrm{O}_{3}$ nanoparticle shape has any effect on the thermal conductivity and viscosity of ILs based nanofluids. 


\section{EXPERIMENTAL PROCEDURE}

\subsection{Material Selection and Nanofluids Preparation}

The ILs based nanofluids were prepared by pouring 1-Butyl-3-methylimidazolium bis(trifluoromethylsulfonyl)imide base $\mathrm{IL}$ and $\mathrm{Al}_{2} \mathrm{O}_{3}$ nanoparticles in to a glass vial measuring $60 \mathrm{~g}$ of total solution, with the nanoparticles concentration being $1 \mathrm{wt} \%$ in nanofluids. The solution was mixed by vortex mixture for approximately one hour to remove possible agglomerations and suspend the particles in the base IL. Three different particle shapes (needle, rod, and spherical) were purchased from Meliorum Technologies. Needle shape have dimension 2-5 nm diameter and 70-100 $\mathrm{nm}$ length, rod shape is $10 \mathrm{~nm}$ diameter and $100 \mathrm{~nm}$ length, and spherical shape is $10 \mathrm{~nm}$ diameter. Fig. 1 represents SEM image of $10 \mathrm{~nm}$ spherical, and rod shape nanoparticles in ionic liquids. SEM image were taken from the Applied Research Center (ARC), Aiken.
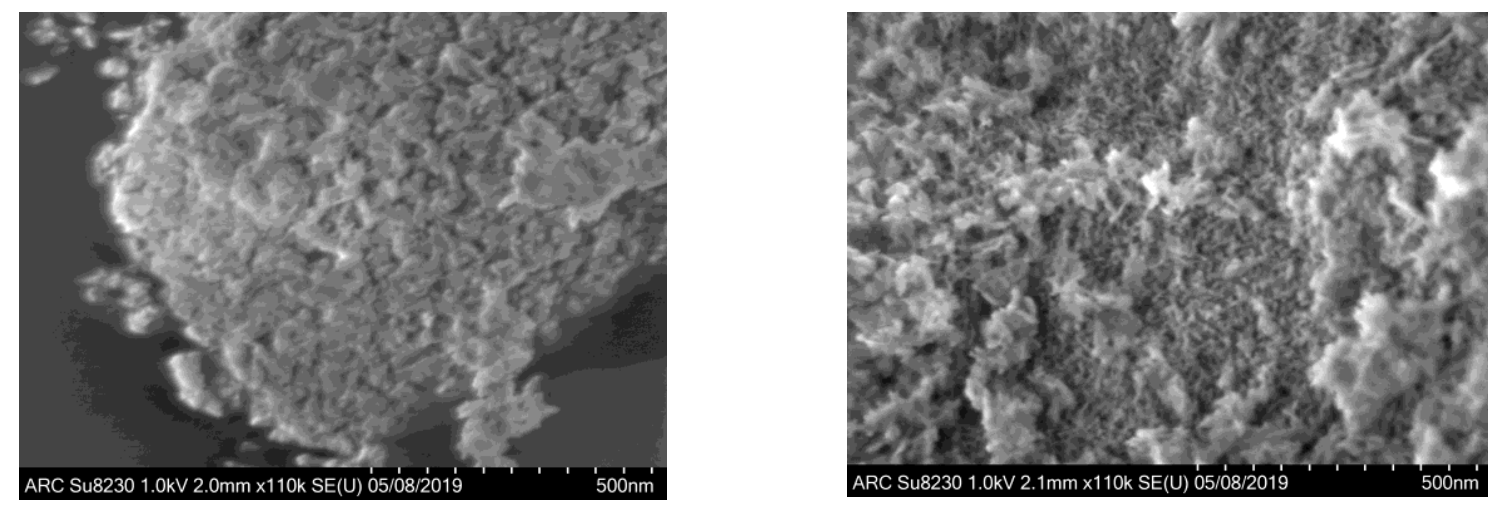

Figure 1: SEM image of spherical and rod nanoparticles in ionic liquids.

The Base IL is having a purity of $99.5 \%$ and a molecular weight of $419.37 \mathrm{~g} / \mathrm{mol}$. was purchased from IoLiTec Inc. (Germany). Chemical structure of cation and anion of the IL is presented in Fig.2.<smiles>CCCCn1cc[n+](C)c1</smiles>

Cation<smiles>O=S(=O)([N-]S(=O)(=O)C(F)(F)F)C(F)(F)F</smiles>

Anion

Figure 2: Chemical structure of cation and anion of $\left[\mathrm{C}_{4} \mathrm{mim}\right]\left[\mathrm{NTf}_{2}\right]$

\subsection{Measurements of Thermal conductivity and Viscosity}

The thermal conductivity of ILs based nanofluids was measured using a KD2 Pro thermal property analyzer (Decagon Device, USA). The KD2 Pro uses the transient line heat source method to measure thermal conductivity, resistivity, diffusivity, and specific heat [12]. The thermal conductivity of ILs based nanofluids was measured at temperatures ranging from $10-70^{\circ} \mathrm{C}$.

The viscosities of ILs based nanofluids was measured by a cone and plate type rotary viscometer (LVDVII+ProCP from Brookfield Engineering Co.). The sample size of the cone and plate arrangement is $1 \mathrm{~mL}$. The thermal jacket of the viscometer and the thermal bath (Thermo NESLAB) was maintained the temperature of the sample.

\section{RESULTS AND DISCUSSIONS}

Fig. 3, shows thermal conductivity of ILs based nanofluids compared with the base fluids and all of the $1 \%$ wt\% ILs bases nanofluids shows higher thermal conductivity compared to the base ILs. From all of the ILs based nanofluids, needle shape nanoparticles shows the highest thermal conductivity enhancement. The thermal conductivity of base ILs and ILs based nanofluids does not significantly depends on the temperature 
and in all temperature there are almost $8 \%$ increase in thermal conductivity was observed. Other researchers observed similar enhancement of thermal conductivity [13-14] where the nanofluids were synthesis by $\mathrm{Al}_{2} \mathrm{O}_{3}$ and multi-wall carbon nanotubes (MWCNTs). One of the possible reason for needle shape having higher thermal conductivity enhancement is the aspect ratio of the nanoparticles [15].

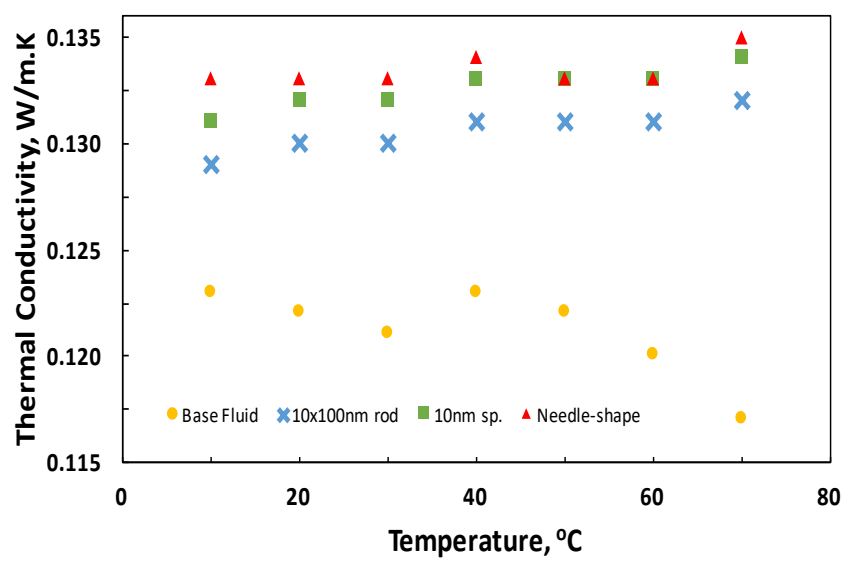

Figure 3: Nanoparticle shape effect on thermal conductivity of ILs based nanofluids

Viscosity measurement for all of the ILs based nanofluids were measured in the temperature range of 10$90^{\circ} \mathrm{C}$. Regardless the shape of the nanoparticles, ILs based nanofluids show shear thinning behavior where viscosity decreases with increase in shear rate. Fig. 4 presents the rheological behavior of $1 \mathrm{wt} \%$ rod shape ILs based nanofluids at temperature $30^{\circ} \mathrm{C}$.

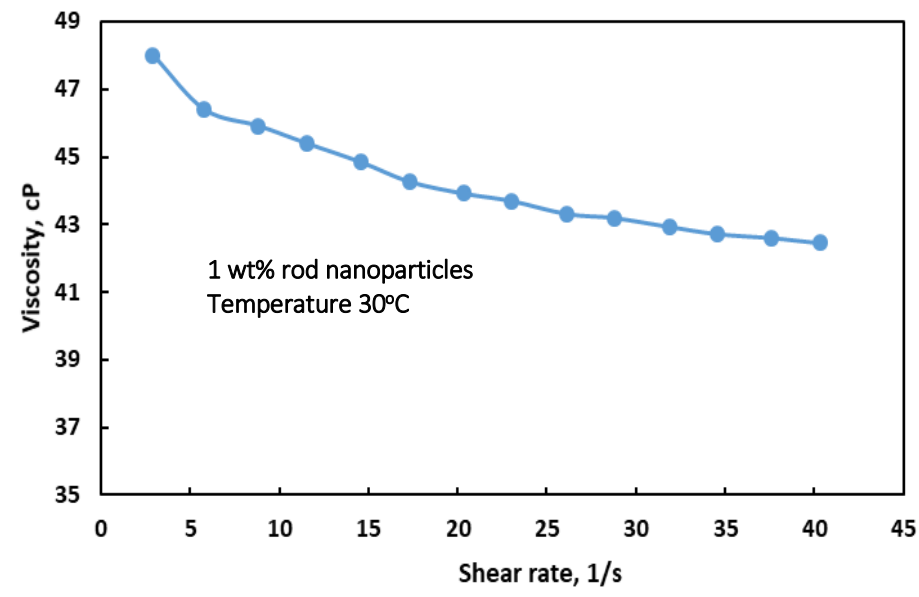

Figure 4: Rheological behavior of ILs based nanofluids (1 wt $\%$ rod shape nanoparticles and $\left.30^{\circ} \mathrm{C}\right)$

Fig. 5. shows the viscosity of $1 \mathrm{wt} \%$ ILs based nanofluids compared with the base ILs and for all of the shapes nanofluids shows higher viscosity compared to the base ILs. Based on the shape there is no significant difference in viscosity of ILs based nanofluids was observed. Viscosity of IL and Ils based nanofluids is sharply decrease with temperature increases. There is interesting things to notice that at low temperature the enhancement of viscosity is much higher however at high temperature viscosity of ILs based nanofluids is not that much higher than the base ILs. As we know viscosity of fluid is directly related to the pumping power, at higher temperature ILs based nanofluids will not hindering the enhancement of heat transfer performance of CSP system. 


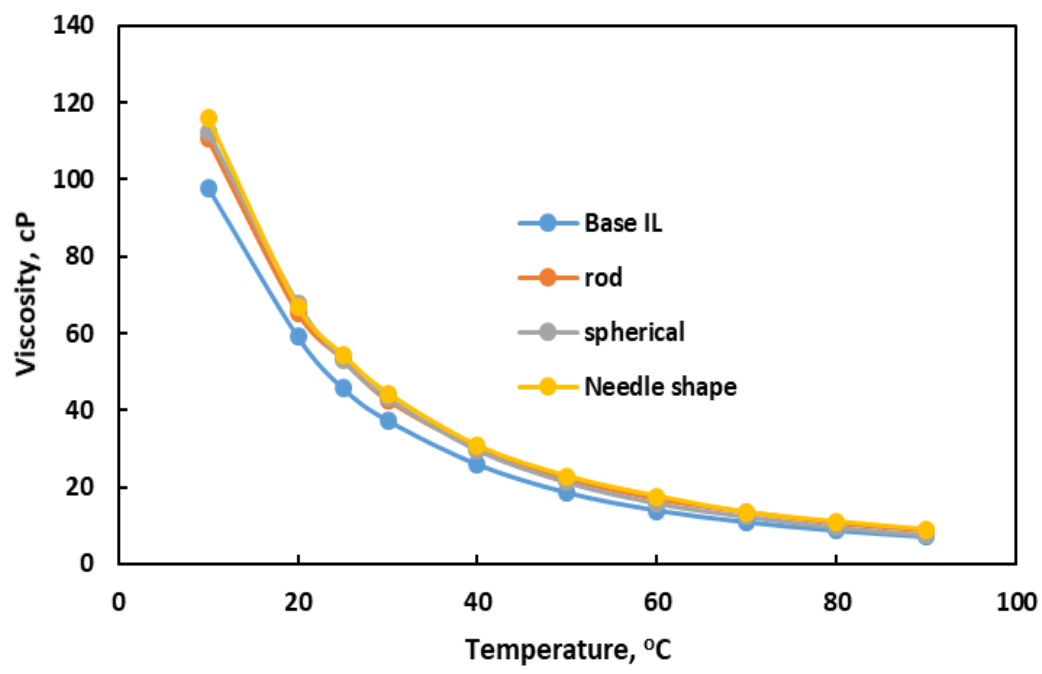

Figure 5: Nanoparticle shape effect on viscosity of ILs based nanofluids

\section{CONCLUSIONS}

Thermal conductivity and viscosity of ILs based nanofluids with different shape nanoparticles were measured and reported. Following conclusions can be drawn from the experimental results:

- Maximum 8\% thermal conductivity enhancement was observed for needle shape nanoparticles having $1 \mathrm{wt} \%$ concentration.

- No significant effect of temperature was observed for the thermal conductivity of base ILs and ILs based nanofluids.

- ILs based nanofluids show shear thinning behavior where viscosity decreases with increase in shear rate.

- Viscosity of ILs based nanofluids is higher than the base fluid and viscosity sharply decreases with increase in temperature.

- No significant effect of shape of nanoparticles was observed for ILs based nanofluids.

\section{ACKNOWLEDGMENT}

The financial support of this project is from Magellan Scholar Award program of University of South Carolina, Summer Scholar Institute (SSI) from University South Carolina Aiken, and Vice-President of Research, University of South Carolina under the Advanced Support for Innovative Research Excellence (ASPIRE I) program.

\section{REFERENCES}

[1] T. Welton,Room-Temperature Ionic Liquids: Solvents for Synthesis and Catalysis, Chemical Reviews. 99(1999) 2071-2083.

[2] R.D.Rogers,K. R. Seddon, Ionic Liquids-Solvents of the Future? Science. 302(2003) 792-793.

[3] M. Eck, K. Hennecke, Heat transfer fluids for future parabolic trough solar thermal power plants, ISES Solar World Congress 2007, ISES Solar World Congress, Beijing (China) S. 1806 - 1812.

[4] H. Muller-Steinhagen, F. Trieb, Concentrating solar power: a review of the technology, Ingenia. (2004) 43-8.

[5] Stephen U. S. Choi and J. A. Eastman, "Enhancing Thermal Conductivity of Fluids with Nanoparticles" ASME International Mechanical Engineering Congress \& Exposition, November 12- 
17, 1995, San Francisco, CA.

[6] C. A. Nieto de Castro, M. J. V. Lourenco, A. P. C. Ribeiro, E. Langa, and S. I. C. Vieira, Thermal Properties of Ionic Liquids and IoNanofluids of Imidazolium and Pyrrolidinium Liquids. Journal of Chemical Engineering Data. 55 (2010) 653-661.

[7] C.A. Nieto de Castro, S.M.S. Murshed, M.J.V. Lourenço, F.J.V. Santos, M.L.M. Lopes, J.M.P. França, "Enhanced thermal conductivity and specific heat capacity of carbon nanotubes ionanofluids" International Journal of Thermal Sciences. 62(2012) 34-39.

[8] T.C. Paul, A.K.M.M. Morshed, E. B. Fox, J. A. Khan, "Enhanced thermophysical properties of NEILs as heat transfer fluids for solar thermal applications" Applied Thermal Engineering 110 (2017) 1-

[9] T. C. Paul, A.K.M. M. Morshed, E. B. Fox, J. A. Khan, Thermal performance of $\mathrm{Al}_{2} \mathrm{O}_{3}$ Nanoparticle Enhanced Ionic Liquids (NEILs) for Concentrated Solar Power (CSP) applications, International Journal of Heat and Mass Transfer 85 (2015) 585-594.

[10] E. V. Timofeeva, J.L. Routbort, D. Singh, "Particle shape effects on thermophysical properties of alumina nanofluids" Journal of Applied Physics 106, 014304 (2009).

[11] Y. Ji, C. Wilson, H.Chen,H. Ma, "Particle shape effect on heat transfer performance in an oscillating heat pipe" Nanoscale Research Letters 2011, 6:296.

[12] "KD2 PRO - Product Overview." DECAGON DEVICES, ww.decagon.com/en/thermal/instruments/kd2-pro/

[13] E. B. Fox, A. E. Visser, N. J. Bridges, J. W. Amoroso, Thermophysical properties of nanoparticleenhanced ionic liquids(NEILs) heat-transfer fluids, Energy Fuels27 (6) (2013) 3385-3393.

[14] C. A. Nieto de Castro, M. J. V. Lourenco, A. P. C. Ribeiro, E. Langa, and S. I. C. Vieira, Thermal Properties of Ionic Liquids and IoNanofluids of Imidazolium and Pyrrolidinium Liquids. Journal of Chemical Engineering Data. 55 (2010) 653-661.

[15] E.V. Timofeeva, J. L. Routbort, D. Singh, "Particle shape effects on thermophysical properties of alumina nanofluids" Journal of Applied Physics 106, 014304 (2009) 